Çukurova Üniversitesi Mühendislik Mimarlık Fakültesi Dergisi, 31(2), ss. 119-128, Aralık 2016

Çukurova University Journal of the Faculty of Engineering and Architecture, 31(2), pp. 119-128, December 2016

\title{
Farklı Isıtma-Derece-Gün (HDD) Değerlerine Bağlı Olarak Seralarda Isı Enerjisi Gereksiniminin Belirlenmesi
}

\author{
A. Nafi BAYTORUN ${ }^{* 1}$, Sait ÜSTÜN ${ }^{2}$, Adil AKYÜZ ${ }^{2}$ \\ ${ }^{1}$ Ç.Ü Ziraat Fakültesi Tarımsal Yapılar ve Sulama Bölümü, Adana \\ ${ }^{2}$ KSÜ Ziraat Fakültesi Biyosistem Mühendisliği Bölümü, Kahramanmaraş
}

Geliş tarihi: 01.06.2016 Kabul tarihi: 23.11.2016

Öz

Seralarda üretim periyodu boyunca ortaya çıkan 1S1 enerjisi gereksinimi, üretim ekonomisinin belirlenmesi ve yapılacak fizibilite çalışmaları için önemlidir. Seralarda ısı enerjisi gereksinimi DIN 4701 standartlarında belirlenen esaslara göre ortalama sıcaklık değerlerinden gidilerek belirlenmektedir. Ancak ortalama değerlere göre yapılan hesaplamalar sıcaklık ortalamasının yüksek olduğu geçiş dönemlerinde yanıltıcı sonuçların ortaya çıkmasına neden olmaktadır. Seralarda 1sı enerjisi gereksinimi saatlik iklim değerlerine göre en sağlıklı olarak hesaplanabilmektedir.

Yapılan bu çalışmada, Türkiye'de seracılığın yaygın olarak yapıldı̆̆ı ve ısıtma kaynakları açısından seracılık potansiyeline sahip farklı illerin Isıtma Derece-Gün (HDD) değerleri ile ISIGER-SERA uzman sistemle saatlik iklim değerlerine göre hesaplanan isı enerjisi gereksinimi arasındaki istatistiksel ilişkiler belirlenmiştir. Serada gerçek $1 \mathrm{~S} 1$ enerjisi elde edilen istatistiksel ilişkilere göre kolayca belirlenebilmektedir. Ancak elde edilen 1s1 enerjisi gereksinimleri, seranın tipine $\left(A_{H} / A_{G}\right)$ ve serada kullanılan 1sıtma sistemine bağlı olarak geliştirilen katsayılar yardımıyla düzeltilmelidir. Elde edilen sonuçlar farklı HDD değerlerine sahip bölgelerde kurulacak farklı donanımlara sahip seralarda 1S1 enerjisinin kolayca belirlenmesine olanak sağlamaktadır.

Anahtar Kelimeler: Sera, Isitma, Isıtma derece-gün, Isı enerjisi

\section{Determination of Heat Energy Requirements for Greenhouses in Regions with Different Heating-Degree-Day (HDD) Values}

\begin{abstract}
The heat energy requirement in greenhouses throughout the production period is important in determining the production economy and feasibility studies to be conducted. Heat energy requirement in greenhouses is determined according to DIN 4701 standards by using mean heat temperatures. However, the calculations based on mean temperature causes misleading results in transition periods and in places where mean temperature is high. In order to have the most accurate heat energy requirement of a greenhouse, the hourly climate data should be used.
\end{abstract}

\footnotetext{
* Sorumlu yazar (Corresponding author): A. Nafi BAYTORUN, baytorun@cu.edu.tr
} 
In this study, the statistical correlations between the data of heating-degree-day (HDD) and heat energy requirements calculated by ISIGER-SERA expert system were determined for the provinces having potential of heating sources and where greenhouse are widely used in Turkey. The real heat energy requirement of the greenhouse is determined with the aid of coefficients calculated with the heat energy requirements obtained from statistical methods, type of the greenhouse $\left(\mathrm{A}_{\mathrm{H}} / \mathrm{A}_{\mathrm{G}}\right)$ and heating system used in the greenhouse. The obtained results become easier to determine the heat energy requirements of the greenhouses to be installed in different regions having different HDD values and different equipment.

Keywords: Greenhouse, Heating, Heating degree-day, Heating energy

\section{GíRiș}

Farklı dönemlerde ortaya çıkan enerji krizleri serada üretimin ılıman iklim bölgelerine kaymasına neden olmuştur. Orta ve kuzey Avrupa ülkelerindeki seralar Akdeniz bölgesinde kurulan seralardan daha modern ve karmaşık olup tüm yıl boyunca bitkilerin arzuladıkları gelişim etmenlerini (sıcaklık, nem, ışınım ve $\mathrm{CO}_{2}$ ) optimum düzeyde tutmak zorundadırlar.

Akdeniz bölgesindeki seralar ise makul yatırım bedelleri ile kurulup bitki gelişim etmenlerini ucuz işletme yatırımları ile optimum düzeyde tutmaya çalışan yapılardır. Ancak Akdeniz bölgesinde yapılan seracılıkta, sıcak yaz aylarında seraların boş bırakılması nedeniyle üretim periyodu kısadır. $\mathrm{Bu}$ durum birim alandan elde edilen verimin düşmesine neden olmaktadır.

Soğuk iklim bölgelerinde kurulan seralar, yllın uzun dönemlerinde 1sitılmak zorundadır. Ilıman iklim bölgelerinde ise 1sıtma süresi daha kısa olup 1sıtma gereksinimi kış aylarında ortaya çıkmaktadır. İsrail gibi sıcak iklim ve Akdeniz gibi ılıman iklim bölgelerinde, 1sı gereksinimi kış aylarının sadece gece saatlerinde ortaya çıkmaktadır.

Akdeniz bölgesi seralarında 1sı enerjisi gereksinimi soğuk kuzey Avrupa ülkelerine göre çok daha azdır. De Pascale ve Maggio'ya [1] göre, güney İtalya'da 1 ha'lı kesme çiçek serası için 5200-6800 GJ y1 ${ }^{-1}$ 1S1 enerjisi gereksinimi ortaya çıkarken, Hollanda'da bu değer $16000 \mathrm{GJ}_{\mathrm{y}} \mathrm{l}^{-1}$ olmaktadir.
Kuzey ve güney Avrupa ülkelerinde kurulan seralarda gereksinilen yakıt tüketimleri ciddi anlamda farkl1lık göstermektedir. Kuzey Avrupa ülkelerinde ihtiyaç duyulan yakıt miktarı, güney Avrupa ülkelerinin 10 - 13 katı olmaktadır [2]. Kuzey Avrupa ülkelerindeki seralarda 1s1 enerjisi gereksinimi $1900 \mathrm{MJ} \mathrm{m}^{-2} \mathrm{a}^{-1}\left(528 \mathrm{kWh} \mathrm{m}^{-2} \mathrm{a}^{-1}\right)$ iken, bu değer orta Avrupa ülkeleri için $1500 \mathrm{MJ}$ $\mathrm{m}^{-2} \mathrm{a}^{-1}\left(417 \mathrm{kWh} \mathrm{m}^{-2} \mathrm{a}^{-1}\right)$, güney Avrupa ülkeleri için $500 \mathrm{MJ} \mathrm{m}^{-2} \mathrm{a}^{-1}\left(139 \mathrm{kWh} \mathrm{m}^{-2} \mathrm{a}^{-1}\right)$ olmaktadır. Kuzey Avrupa ülkelerinde $1900 \mathrm{MJ} \mathrm{m}^{-2} \mathrm{a}^{-1}$ is enerjisi gereksinimi için üretim periyodu boyunca $45 \mathrm{l} \mathrm{m}^{-2}$ fueloile ihtiyaç duyulurken, orta Avrupa ülkelerinde $35 \mathrm{~lm}^{-2}$, Güney Avrupa ülkelerinde 12 $l \mathrm{~m}^{-2}$ fueloile ihtiyaç duyulmaktadır [3].

Avrupa'nın 7 ayrı ülkesinde standartlara göre inşa edilen seralarda birim alana bağlı olarak gereksinilen yıllık 1si enerjisi değerleri Garcia vd. [4] tarafından hesaplanmıştır. Yapılan hesaplamalarda en yüksek 1s1 enerjisi gereksinimi Almanya'da (453 $\left.\mathrm{kWh} \quad \mathrm{m}^{-2} \mathrm{a}^{-1}\right)$ en düşük Almeria'da (Íspanya) $\left(88 \mathrm{kWh} \mathrm{m}^{-2} \mathrm{a}^{-1}\right)$ ortaya çıkmıştır. Akdeniz ikliminden kuzeye doğru çıkıldıkça 1sı enerjisi gereksiniminde ciddi artı̧̧lar meydana gelmektedir.

Akdeniz bölgesi daha az 1S1 enerjisi gereksinimi açısından orta ve kuzey Avrupa ülkelerine göre büyük bir avantaja sahiptir. Ancak yılın belli dönemlerinde yüksek sıcaklık nedeniyle serada üretimin yapılmaması elde edilen verim açısından bir dezavantaj yaratmaktadır.

Akdeniz bölgesinde küçük aile tipi işletmelerde bulunan seralar basit yöntemlerle düşük sıcaklıklara karşı korunmaktadırlar. Ancak son ylllarda Akdeniz bölgesinde inşa edilen modern 
seralarda düzenli 1sıtma yapılmaktadır. $\mathrm{Bu}$ seralarda çoğunlukla isı koruma önlemleri tam olarak uygulamadan, çevre üzerinde olumsuz etkileri olan fosil enerji kaynakları kullanılarak isitma yapilmaktadir.

Seralarda 1sı enerjisi gereksinimi farklı yöntemlere göre hesaplanmaktadır. En çok kullanılan yöntemlerden biri ortalama sıcaklık değerlerine göre yapılan hesaplamalardır. Bu yönteme göre yapılan hesaplamalarda ısıtma zamanı çoğunlukla kabul edilerek veya sadece gece uzunluğu dikkate alınarak 1s1 enerjisi gereksinimi belirlenmektedir.

Türkiye'de seracılığın yaygın olarak yapıldı $\breve{g}$ Akdeniz bölgesinin farklı illeri için değişik araştırıcılar tarafindan farklı yöntemlere göre yapılan 1s1 enerjisi hesaplamaları Çizelge 1'de verilmiştir [5].

Çizelge 1. Akdeniz bölgesinde farklı iller için plastik serada sicaklığın $16^{\circ} \mathrm{C}^{\prime} \mathrm{de}$ tutulduğu koşullarda farklı yöntemlere göre hesaplanan 1S1 enerjisi gereksinimleri

\begin{tabular}{|c|c|c|c|}
\hline \multirow[b]{2}{*}{ İller } & \multicolumn{3}{|c|}{$\begin{array}{l}\text { Is1 Enerjisi Gereksinimi } \\
\left(\mathrm{kWh} \mathrm{m}^{-2} \mathrm{a}^{-1}\right)\end{array}$} \\
\hline & 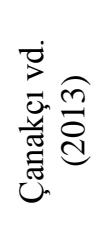 & 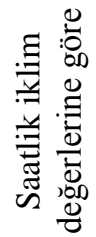 & 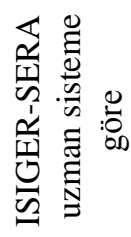 \\
\hline Antalya & 147,1 & 114,6 & 101,0 \\
\hline Muğla & 290,5 & 217,1 & 203,6 \\
\hline Mersin & 99,8 & 88,7 & 76,8 \\
\hline Adana & 156,2 & 102,9 & 90,8 \\
\hline Hatay & 159,9 & 121,8 & 109,5 \\
\hline
\end{tabular}

Çanakçı ve arkadaşları [6] PE plastik seralarda sicaklığın gece/gündüz $16 / 18^{\circ} \mathrm{C}$ 'de tutulmak istenmesi durumunda ihtiyaç duyulan 1S1 enerjisi gereksinimini, serada arzulanan sicaklık ile gece saatlerinde ortaya çıkan ortalama sıcaklık farkını ve her ayın gece uzunluğunu dikkate alarak belirlemişlerdir. Çizelgeden de görüleceği gibi Çanakçı ve arkadaşları [6] Akdeniz bölgesindeki farklı iller için yaptıkları hesaplamalarda yıllık 1sı enerjisi gereksinimleri 100-290 $\mathrm{kWh} \mathrm{m}^{-2} \mathrm{a}^{-1}$ arasında bulmuşlardır. Aynı illerimiz için saatlik iklim değerlerinden gidilerek DIN 4701 standartlarında belirlenen esaslara göre yapılan hesaplamalardan elde edilen değerler 89-204 $\mathrm{kWh} \mathrm{m}^{-2} \mathrm{a}^{-1}$ arasında değişmektedir [5].

Zabeltitz [7] yaptığı hesaplamalarda sera kurulan yerin enlem derecesi, gün uzunluğu ve serada ortaya çıkan sıcaklık yükselmelerini dikkate alarak Akdeniz ülkelerindeki farklı yerler için 1sı enerjisi gereksinimini belirlemiştir. Zabeltitz Antalya için serada sicaklığın $16^{\circ} \mathrm{C}$ 'de tutulmak istenmesi durumunda üretim periyodu boyunca 1S1 enerjisi gereksinimini gece saatleri için $56,1 \mathrm{kWh} \mathrm{m}^{-2} \mathrm{a}^{-1}$ olarak hesaplamıştır.

Seralarda 1S1 gereksiniminin ortalama sicaklık değerlerinden gidilerek hesaplanması sıcaklığın yüksek olduğu geçiş dönemleri ve serada sıcaklığın düşük tutulduğu koşullarda yanıltıcı sonuçlara neden olabilmektedir [8,9].

Seralarda 1S1 enerjisi gereksinimi, saatlik iklim değerlerine göre en doğru hesaplanmaktadır $[10,11,7,9]$. Ancak saatlik iklim değerlerinin elde edilmesi güç olup yapılan hesaplamalar oldukça fazla zaman almaktadır.

DIN 4701 standartlarında belirlenen esaslara göre, seralarda 1s1 enerjisi hesaplamalarında kullanılan toplam 1sı gereksinim katsayısı $\left(u_{c s}\right)$, rüzgar hızına bağlı olarak değişmektedir. Literatürlerde verilen toplam 1sı gereksinim katsayısı $\left(u_{c s}\right)$ genelde rüzgar hızının $4 \mathrm{~m} \mathrm{~s}^{-1}$ olduğu koşullar için geçerlidir. Saatlik iklim değerlerine göre yapılan hesaplamalarda $u_{c s}$ katsayısı, saatlik rüzgar hızına göre yeniden belirlenerek hesaplamalara katılmalıdır.

DIN 4701 standartlarına göre serada 1S1 enerjisi gereksiniminin hesaplanmasinda, serada arzulanan sıcaklık ve dış sıcaklık arasındaki fark dikkate alınmaktadır. Ancak 1sitılmayan ve belirli bir sıcaklığa kadar havalandırılmayan seralarda ortaya çıkan gerçek sıcaklık değerleri, diş sıcaklık değerlerinden yüksektir. Belirtilen nedenle hesaplamalarda dış sıcaklık yerine hesaplanan teorik sıcaklık, serada arzulanan sicaklik ve 
havalandırma sıcaklığına bağlı olarak belirlenen gerçek sera sıcaklığı dikkate alınmalıdır [11]. Ayrıca 1lıman iklim bölgelerinde kurulan seralarda gün boyu depolanan isı enerjisi, serada sicaklık yükselmelerine neden olmaktadır. Belirtilen nedenle serada 1 s1 enerjisi gereksiniminin belirlenmesinde, serada ortaya çıkan gerçek sıcaklık ve sıcaklık yükselmeleri dikkate alınarak yapılan hesaplamalar daha gerçekçi sonuçlar vermektedirler [11]. Zabeltitz [7] Akdeniz Bölgesi için seralarda sıcaklık yükselmelerinin $1-2^{\circ} \mathrm{C}$ alınabileceğini ifade etmektedir.

Baytorun ve arkadaşları [5] Rath [11] tarafindan geliştirilen matematiksel modeli kullanarak, yukarıda belirtilen sakıncaları ortadan kaldıran ve saatlik iklim değerlerine bağlı 1S1 enerjisi gereksinimini hesaplayabilen ISIGER-SERA uzman sistemi geliştirmişlerdir. ISIGER-SERA uzman sistemle, farklı donanımlara sahip seraların farklı sıcaklık değerlerinde gereksindikleri 1sı enerjisinin hesaplanması yanında, 1sıtma sistemlerinin projelenmesi için gerekli olan parametrelerin de belirlenmesi mümkün olabilmektedir. Ancak bu programın kullanılması bilgisayar desteği gerektirmektedir.

Bir yerin iklim sertliği Derece-Gün cinsinden hassasiyetle karakterize edilebilmektedir. Tüm dünyada özellikle 1sıtma ve 1s1 yalıtımı uygulamaları için Derece-Gün sayıları kullanılarak coğrafik bölgelerden farklı olarak Derece-Gün bölgeleri tespit edilmektedir [12,13,14].

Yapılan bu çalışmada son yıllarda Türkiye'de kurulan sera boyutları dikkate alınarak farklı donanımlara sahip PE plastik seralar için ISIGERSERA uzman sistemle hesaplanan 1S1 enerjisi gereksinimi ile, Isıtma-Derece-Gün değerleri arasındaki ilişkilerin belirlenmesi ve elde edilen nomogram yardımıyla Isıtma-Derece-Gün değerlerine göre farklı bölgeler için 1sı enerjisi gereksiniminin belirlenmesi amaçlanmıştır.

\section{MATERYAL VE METOT}

Hesaplamalarda gerekli olan Isıtma-Derece-Gün (HDD) değerleri, Bulut ve arkadaşları [15] tarafından eşitlik 1 'e göre $16^{\circ} \mathrm{C}$ eşik sıcaklığı için hesaplanmış değerler alınmıştır.

$$
\operatorname{HDD}\left(\vartheta_{\mathrm{h}}\right)=\sum_{1}^{\mathrm{N}}\left(\vartheta_{\mathrm{h}}-\vartheta_{\mathrm{o}}\right)
$$

ISIGER-SERA uzman sistem yardımıyla serada 1S1 enerjisi gereksinimi eşitlik 2 yardımı ile hesaplanmıştır. Eşitlikte bulunan değişkenlerin belirlenmesi Baytorun [2] tarafından yapılan çalışmada detaylı verilmiştir. Hesaplamalarda kullanılan seranın boyutları Çizelge 2'de verilmiştir.

$$
\begin{aligned}
& \mathrm{Q}_{\mathrm{cs}}=\sum_{n=1}^{8760}\left(\left(\left(\vartheta_{\mathrm{i}_{\mathrm{n}}}-\vartheta_{\mathrm{i}, \mathrm{oH}}-\Delta \vartheta_{\mathrm{n}}\right) * \mathrm{u}_{\mathrm{cs}} *\right.\right. \\
& \left.\left.\sum_{\mathrm{r} \mathrm{HFa}} \mathrm{A}_{\mathrm{r}} *\left(1-\mathrm{EE}_{\mathrm{ES}_{\mathrm{n}}}\right)\right) * \mathrm{t}_{\mathrm{si}}\right)
\end{aligned}
$$

Eşitlikte;

$\mathrm{Q}_{\mathrm{cs}}:$ Seranın yıllık 1sı enerjisi gereksinimi $(\mathrm{Wh})$

$\vartheta_{i} \quad$ : Serada arzulanan sicaklık değeri $\left({ }^{\circ} \mathrm{C}\right)$

$\vartheta_{i, O H}$ : Isıtmasız serada ortaya çıkan sıcaklık $\left({ }^{\circ} \mathrm{C}\right)$

$\Delta \vartheta_{s p}$ : Serada ortaya çıkan sıcaklıyükselmesi $\left({ }^{\circ} \mathrm{C}\right)$

$u_{c s}:$ Seranın 1 sı gereksinim katsayısı $\left(\mathrm{W} . \mathrm{m}^{-2} \mathrm{~K}^{-1}\right)$

$A_{r} \quad$ : Örtü yüzey alanı $\left(\mathrm{m}^{2}\right)$

$E E_{E S}$ : Isı perdesi ile sağlanan 1sı tasarrufu (-)

$n \quad:$ Yilın saatleri

$t_{s i} \quad$ Simulasyon zaman dilimi $(1 \mathrm{~h})$

Çizelge 2. Hesaplamalarda kullanılan PE plastik seranın boyutları

\begin{tabular}{|l|c|r|}
\hline Bölme sayısı & $($ Adet $)$ & 10 \\
\hline Bölme genişliği & $(\mathrm{m})$ & 9,60 \\
\hline Sera uzunluğu & $(\mathrm{m})$ & 50,0 \\
\hline Yan duvar yüksekliği & $(\mathrm{m})$ & 4,25 \\
\hline Çatı yüksekliği & $(\mathrm{m})$ & 2,75 \\
\hline Örtü alanı & $\left(\mathrm{m}^{2}\right)$ & 7338,04 \\
\hline Taban alanı & $\left(\mathrm{m}^{2}\right)$ & 4800,0 \\
\hline $\mathrm{A}_{\mathrm{H}} / \mathrm{A}_{\mathrm{G}}$ & $(-)$ & 1,53 \\
\hline
\end{tabular}

\section{BULGULAR}

Türkiye'nin farklı illeri için hesaplanmış IsıtmaDerece-Gün (HDD) değerleri Bulut ve arkadaşları [15] tarafından yapılan çalışmalardan $16^{\circ} \mathrm{C}$ eşik değeri için alınmıştır (Çizelge 3). Çizelgeden de 
görüleceği gibi en düşük Isıtma-Derece-Gün (HDD) değeri Akdeniz bölgesindeki Mersin ilinde ortaya çıkarken, en yüksek HDD değeri Ardahan ilinde görülmektedir.

Çizelge 3. Türkiye'nin farklı illeri için 1sıtma derece-gün (HDD) değerleri [15]

\begin{tabular}{|l|c|l|c|}
\hline Şehir & $16^{\circ} \mathrm{C}$ & Şehir & $16^{\circ} \mathrm{C}$ \\
\hline Adana & 579 & Isparta & 2120 \\
\hline Adapazarı & 1413 & İstanbul & 1433 \\
\hline Adıyaman & 1328 & İzmir & 845 \\
\hline Afyon & 2325 & K. Maraş & 1284 \\
\hline Ağrı & 3867 & Karaman & 2229 \\
\hline Aksaray & 2157 & Kars & 4145 \\
\hline Amasya & 1778 & Kastamonu & 2567 \\
\hline Ankara & 2199 & Kayseri & 2587 \\
\hline Antalya & 731 & Kilis & 1196 \\
\hline Ardahan & $\mathbf{4 4 6 9}$ & Kırıkkale & 2145 \\
\hline Artvin & 1951 & Kırklareli & 1828 \\
\hline Aydın & 867 & Kırşehir & 2365 \\
\hline Balıkesir & 1498 & Kocaeli & 1375 \\
\hline Bartın & 1747 & Konya & 2350 \\
\hline Batman & 1450 & Kütahya & 2360 \\
\hline Bayburt & 3545 & Malatya & 2037 \\
\hline Bilecik & 1933 & Manisa & 1166 \\
\hline Bingöl & 2399 & Mardin & 1621 \\
\hline Bitlis & 2800 & Mersin & $\mathbf{5 5 2}$ \\
\hline Bolu & 2291 & Muğla & 1458 \\
\hline Burdur & 1902 & Muş & 3088 \\
\hline Bursa & 1491 & Nevşehir & 2508 \\
\hline Çanakkale & 1371 & Niğde & 2362 \\
\hline Çankırı & 2370 & Ordu & 1361 \\
\hline Çorum & 2428 & Rize & 1375 \\
\hline Denizli & 1245 & Samsun & 1377 \\
\hline Diyarbakır & 1739 & Siirt & 1577 \\
\hline Edirne & 1791 & Sinop & 1430 \\
\hline Elazı̆̆ & 2211 & Sivas & 2896 \\
\hline Erzincan & 2564 & Şanlıurfa & 1157 \\
\hline Erzurum & 4205 & Tekirdağ & 1586 \\
\hline Eskişehir & 2516 & Tokat & 1938 \\
\hline Gaziantep & 1605 & Trabzon & 1291 \\
\hline Giresun & 1328 & Tunceli & 2280 \\
\hline Gümüşhane & 2702 & Uşak & 1945 \\
\hline Hakkari & 2986 & Van & 2938 \\
\hline Hatay & 797 & Yalova & 1409 \\
\hline Iğdır & 2319 & Yozgat & 2853 \\
\hline & & Zonguldak & 1557 \\
\hline
\end{tabular}

Seracılığın yoğun olarak yapıldığı Akdeniz Bölgesindeki illerde Isıtma-Derece-Gün (HDD) değerleri 552 (Mersin) ile 797 (Hatay) arasında değişmektedir. Ege ve Marmara bölgesinde bu değer 1500'e Jeotermal kaynakların bulunduğu iç Ege ve Orta Anadolu'da 2500'lere kadar yükselmektedir.

Çizelge 4. Farklı 1sıtma-derece-gün değerlerine sahip illerde çatısı tek kat yan duvarları çift kat PE plastikle kaplı seralarda sicaklığın gece/gündüz $16^{\circ} \mathrm{C}$ 'de tutulduğu koşullarda gereksinilen is1 enerjisi

\begin{tabular}{|c|c|c|c|c|}
\hline \multirow[b]{2}{*}{ İl } & \multirow[b]{2}{*}{ 全 } & \multicolumn{3}{|c|}{$\begin{array}{l}\text { Is1 enerjisi gereksinimi } \\
\mathrm{kWh} \mathrm{m}^{-2} \mathrm{a}^{-1}\end{array}$} \\
\hline & & $\begin{array}{l}\frac{N}{v} \\
\frac{d}{0} \\
\frac{d}{0} \\
\vec{a} \\
\vec{a}\end{array}$ & 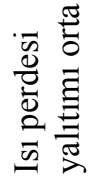 & 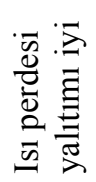 \\
\hline Adana & 579 & 99,6 & 80,7 & 68,9 \\
\hline Mersin & 552 & 84,1 & 67,5 & 57,1 \\
\hline Antalya & 731 & 110,7 & 87,5 & 73,0 \\
\hline Antakya & 797 & 120,7 & 97,8 & 83,4 \\
\hline Aydın & 867 & 139,6 & 114,0 & 98,0 \\
\hline İzmir & 845 & 121,5 & 96,4 & 80,7 \\
\hline Denizli & 1245 & 185,0 & 152,3 & 131,8 \\
\hline Manisa & 1166 & 173,7 & 140,6 & 119,9 \\
\hline Şanlıurfa & 1157 & 165,8 & 135,5 & 116,5 \\
\hline Bursa & 1491 & 221,9 & 182,0 & 157,0 \\
\hline Çanakkale & 1371 & 207,1 & 166,0 & 140,2 \\
\hline K.Maraş & 1284 & 184,9 & 152,2 & 131,7 \\
\hline Muğla & 1458 & 224,5 & 183,6 & 158,0 \\
\hline Ordu & 1361 & 183,8 & 150,4 & 129,4 \\
\hline Samsun & 1377 & 180,7 & 146,7 & 125,4 \\
\hline Yalova & 1409 & 188,9 & 155,1 & 133,9 \\
\hline Ballkesir & 1498 & 236,9 & 194,8 & 168,4 \\
\hline Diyarbakır & 1739 & 272,6 & 222,7 & 191,5 \\
\hline Tekirdağ & 1586 & 228,7 & 185,9 & 159,2 \\
\hline A.Karahisar & 2325 & 360,8 & 297,1 & 257,3 \\
\hline Kırşehir & 2365 & 358,7 & 296,0 & 256,8 \\
\hline Kütahya & 2360 & 366,1 & 305,0 & 266,9 \\
\hline Nevşehir & 2508 & 373,5 & 306,9 & 265,3 \\
\hline
\end{tabular}

ISIGER-SERA uzman sistemle saatlik iklim değerlerinden gidilerek Türkiye'de seracilığın yoğun olarak yapıldığı iller ve jeotermal kaynaklar 
bakımından seracılık potansiyeline sahip iller için, çatısı tek kat yan duvarları çift kat PE plastikle kaplı farklı donanımlara sahip seralarda sıcaklığın $16^{\circ} \mathrm{C}^{\prime}$ de tutulduğu koşullar için üretim periyodu boyunca gereksinilen 1sı enerjisi değerleri hesaplanarak Çizelge 4'te verilmiştir. Çizelgeden de görüleceği gibi illerin Isıtma-Derece-Gün (HDD) değerlerine bağlı olarak serada üretim periyodu boyunca gereksinilen 1sı enerjisi değerleri değişmektedir. ISIGER-SERA uzman sisteme göre yapılan hesaplamalarda en düşük 1S1 enerjisi gereksinimi Mersin ilinde $\left(57,1 \mathrm{kWh} \mathrm{m}^{-2} \mathrm{a}^{-1}\right)$ ortaya çıkarken, en yüksek 1sı enerjisi gereksinimi Nevşehir (265,3 $\left.\mathrm{kWh} \mathrm{m}^{-2} \mathrm{a}^{-1}\right)$ için hesaplanmıştır.

Seralarda istenen gece ve gündüz sıcaklık değerleri üretilen bitki çeşidine bağlı olarak değişmektedir. Seralarda en fazla üretilen domates bitkisi $17-27^{\circ} \mathrm{C}$ sicaklığa adapte olmuștur $[16,17]$. Seralarda domates üretiminde enerji tasarrufu amaciyla gece/gündüz sicaklıkları $16 / 18^{\circ} \mathrm{C}$ 'de tutulmaktadır. Akdeniz bölgesinde seralarda sicaklığın $16^{\circ} \mathrm{C}$ 'de tutulmak istenmesi durumunda gündüz saatlerinde 1sıtmaya ihtiyaç duyulmamaktadır. $\mathrm{Bu}$ bölgede gündüz saatlerinde seralarda sicaklığın $18^{\circ} \mathrm{C}$ veya $20^{\circ} \mathrm{C}$ 'ye yükseltilmesi $1 \mathrm{~S}$ enerjisi gereksinimini fazla etkilememektedir. Çatısı tek kat yan duvarları çift kat PE plastikle kaplı 1sı perdesi yalıtımı orta derecede olan serada, sıcaklığın gece $16^{\circ} \mathrm{C}$, gündüz $16^{\circ} \mathrm{C}, 18^{\circ} \mathrm{C}$ ve $20^{\circ} \mathrm{C}^{\prime} \mathrm{de}$ tutulmak istenmesi durumunda üretim periyodu boyunca birim sera alanı için gece ve gündüz saatlerinde gereksinilen 1S1 enerjisi farklı HDD değerleri için Şekil 1'de verilmiştir.

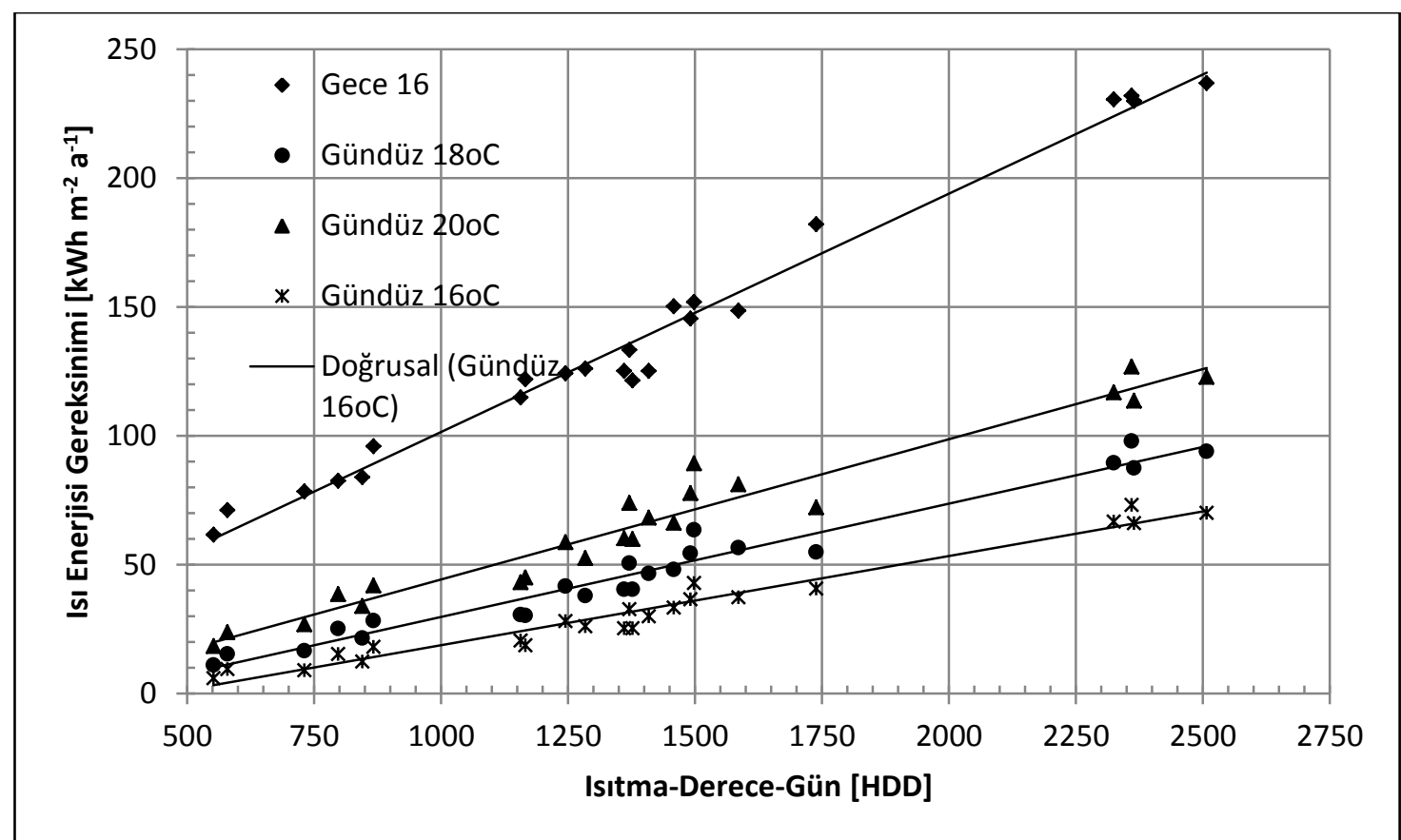

Şekil 1. Çatısı tek, yan duvarları çift kat PE plastikle kaplı ısı perdeli serada sıcaklığın gece $16^{\circ} \mathrm{C}$ ve gündüz $16^{\circ} \mathrm{C}, 18^{\circ} \mathrm{C}, 20^{\circ} \mathrm{C}$ 'de tutulması durumunda HDD değerlerine bağlı gereksinilen isı enerjisi değerleri

Şekil 1'den de görüleceği gibi Isıtma-Derece-Gün (HDD) değeri 1250 olan bir yerde kurulacak PE plastik serada sıcaklığın tüm gün $16^{\circ} \mathrm{C}$ 'de tutulmak istenmesi durumunda, üretim periyodu boyunca gece ve gündüz gereksinilen toplam 1sı enerjisi $124+27=151 \mathrm{kWh} \quad \mathrm{m}^{-2} \quad \mathrm{a}^{-1}$ olurken, gündüz sicaklığın $18^{\circ} \mathrm{C}^{\prime}$ ye yükseltilmesi durumunda bu değer $124+40=164 \mathrm{kWh} \mathrm{m}^{-2} \mathrm{a}^{-1}$ olmaktadır. Diğer bir ifade ile serada gündüz saatlerinde sicaklığın 
$16^{\circ} \mathrm{C}^{\prime}$ den $18^{\circ} \mathrm{C}$ 'ye yükseltilmesi, toplam isı enerjisi gereksinimini $\% 8$ artırmaktadır. Gece $16^{\circ} \mathrm{C}$ ve gündüz farklı sıcaklıklar için yapılan istatistiksel analizler sonucunda çatısı tek kat, yan duvarları çift kat PE plastikle kaplı serada farklı HDD değerleri için elde edilen istatistiksel ilişkiler Çizelge 5'te verilmiştir.

Çizelge 5. Isı perdeli PE plastik serada 1S1 enerjisi ve 1sitma-derece-gün (HDD) değerleri arasındaki istatistiksel ilişkiler

\begin{tabular}{|l|c|c|}
\hline S1caklık & İlişki & $\mathrm{R}^{2}$ \\
\hline Gece $16^{\circ} \mathrm{C}$ & $q=0,092 * \mathrm{HDD}+9,000$ & 0,983 \\
\hline Gündüz $16^{\circ} \mathrm{C}$ & $q=0,034 * \mathrm{HDD}-15,87$ & 0,962 \\
\hline Gündüz $18^{\circ} \mathrm{C}$ & $q=0,043 * \mathrm{HDD}-14,22$ & 0,962 \\
\hline Gündüz $20^{\circ} \mathrm{C}$ & $q=0,054 * \mathrm{HDD}-10,18$ & 0,950 \\
\hline
\end{tabular}

Seralarda Gece/Gündüz 1sı enerjisi tüketim oranı bölge iklimine ve serada istenen sicaklığa bağlı olarak değişmektedir. Ilıman iklimin hakim olduğu yerlerde düşük gündüz sıcaklıkları için gece/gündüz enerji gereksinim oranı 9 olurken,
HDD değerinin büyüdüğü soğuk bölgelerde bu oran 3'e düşmektedir. Ilıman iklim bölgelerinde gündüz sicaklık değerlerinin yükseltilmesi, gece/gündüz enerji tüketim oranını soğuk iklim bölgelerindeki değerlere yaklaştırmaktadır.

Seralarda 1sı enerjisi gereksinimi seranın tipine, dış iklim koşullarına, sera donanımına ve serada arzulanan sıcaklık değerlerine göre değişim göstermektedir. Serada arzulanan sicaklık ve 1s1 perdelerinin yalıtım durumuna bağlı olarak üretim periyodu boyunca gereksinilen 1s1 enerjisinin belirlenmesi için geliştirilen nomogram Şekil 2'de verilmiştir. Geliştirilen bu nomogram yardımıyla herhangi bir yerin Isıtma-Derece-Gün (HDD) değerine, serada istenen sicaklık ve serada kullanılan 1sı perdesinin yalıtımına bağlı olarak, üretim periyodu boyunca gereksinilen isı enerjisi gereksinimi belirlenebilmektedir.

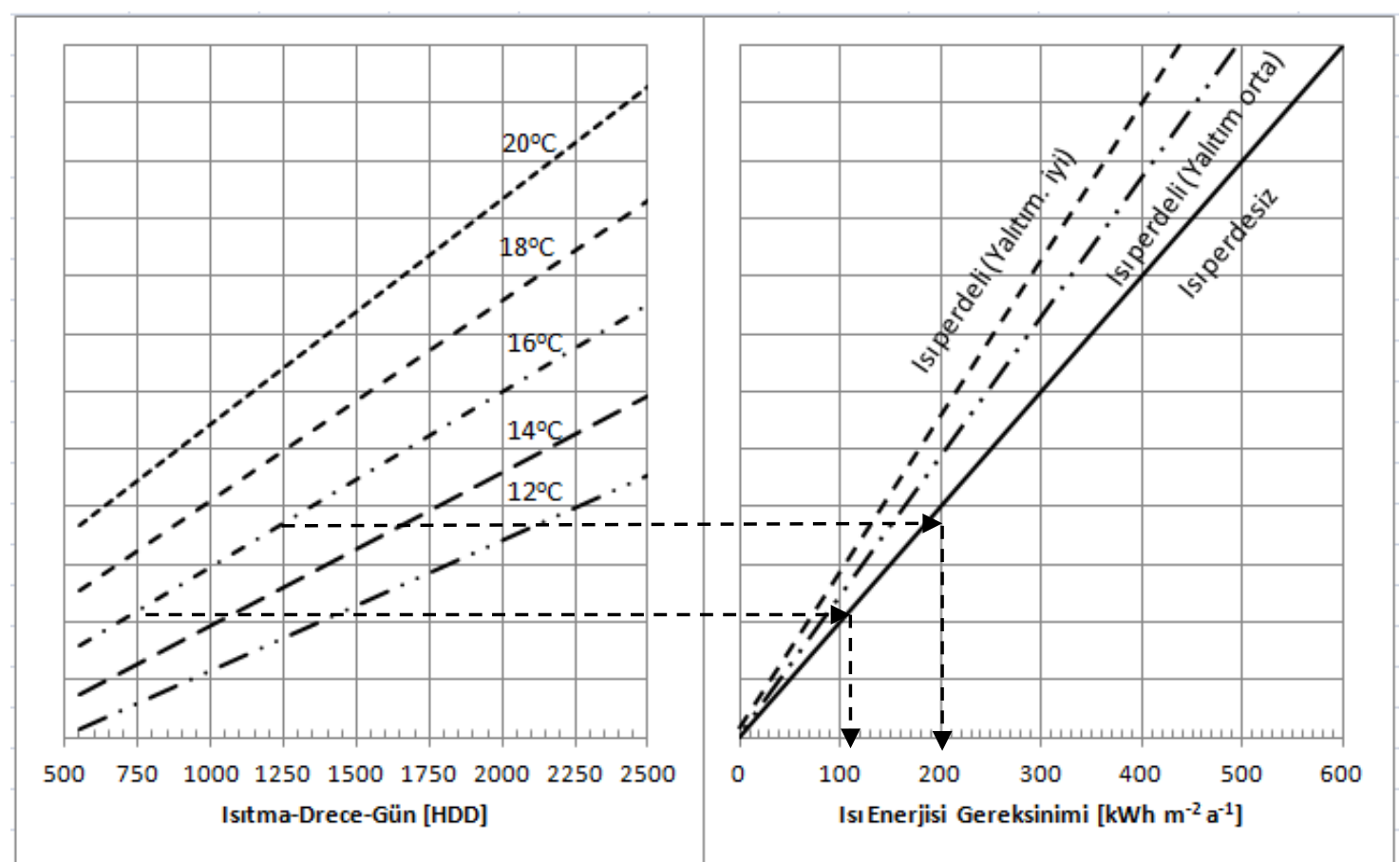

Şekil 2. Çatısı tek yan duvarları çift kat PE plastikle kaplı 1 sı perdeli serada $\left(A_{G} / A_{H}=1,53\right)$ HDD değerlerine bağlı 1sı enerjisi gereksinimi (Isıtma boruları sera tabanına yakın yerleştirilmiş) 
Serada 1S1 enerjisi gereksinimi sera örtü yüzeyinin sera taban alanına oranına bağlı olarak değişmektedir. Serada alan büyüdükçe örtü yüzeyinin taban alanına oranı küçülmektedir. $\mathrm{Bu}$ durum serada birim alan için gereksinilen isı enerjisini de etkilemektedir. Şekil 2'de verilen isı enerjisi gereksinimleri örtü yüzey alanının sera taban alanına oranının $\left(\mathrm{A}_{\mathrm{H}} / \mathrm{A}_{\mathrm{G}}\right)$ 1,53 olduğu sera için geçerlidir. Farklı $A_{H} / A_{G}$ oranına seralar için yapilacak hesaplamalarda Şekil 3 'ten elde edilen düzeltme faktörüyle, Şekil 2'den belirlenen is1 enerjisi gereksiniminin çarpılması gereklidir. Şekil 3 ’ten de görüleceği gibi sera alanı büyüdükçe örtü yüzey alanının sera taban alanına oranı küçülmekte, bu durum 1sı enerjisi gereksinimini de o oranda azaltmaktadır.

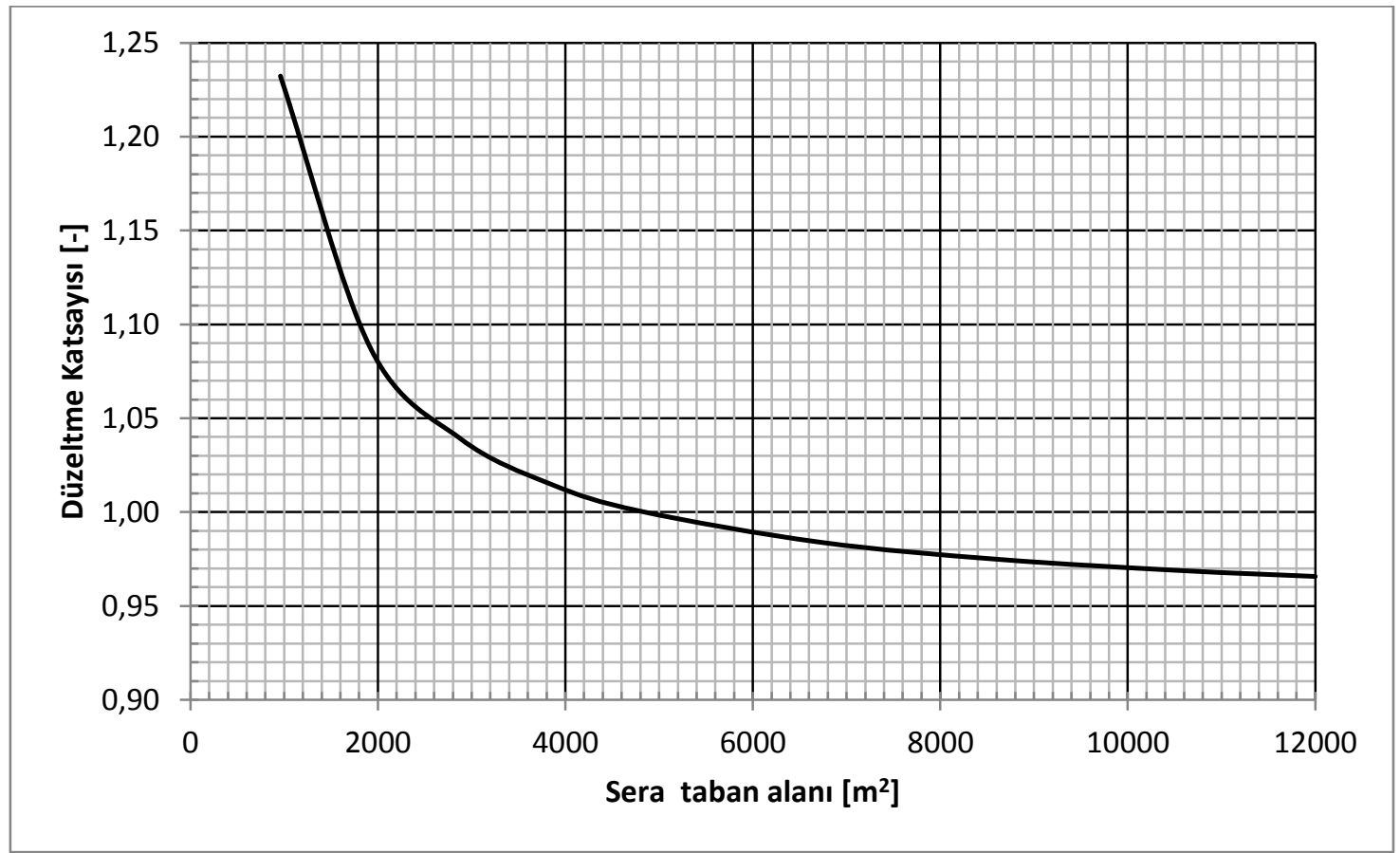

Şekil 3. Sera taban alanına bağlı olarak 1Sı enerjisinin belirlenmesinde gerekli olan düzeltme faktörü

Seralarda üretim periyodu boyunca tüketilen 1s enerjisi, sera 1sıtma sisteminin tipine bağlı olarak değişmektedir. Yapılan hesaplamalarda ısıtma sistemi sera tabanına ve bitki masuralarına yakın olarak kabul edilmiştir. Serada üflemeli ısıtma sistemlerinin kullanılması veya 1sitma borularının seranın yan duvarlarına, çatı bölgesine veya masa altına yerleştirilmesi durumunda enerji tüketimleri farklı olmaktadır [8]. Çizelge 6'da Tantau [8] tarafindan farklı 1sıtma sistemleri için belirlenen 1sı gereksinim katsayılarından yararlanılarak farklı 1sıtma sistemleri için hesaplanan düzeltme faktörleri verilmiştir. Çizelgeden de görüleceği gibi en yüksek 1s1 enerjisi tüketimi 1sıtma borularının sera tavanına yakın yerleştirildiği ve üfleyicili 1sıtıcıların düşük kademelerde çalıştırılması durumunda ortaya çıkmaktadır.

Şekil 2'deki nomogram serada 1sıtma borularının sera tabanına yakın yerleştirildiği koşullar için geçerlidir. Serada farklı 1sıtma sistemlerinin kullanılması durumunda Çizelge 6'da verilen 1sıtma sistemlerinden hangisi kullanılıyorsa, Şekil 2 ve 3 yardımı ile belirlenen 1S1 enerjisi gereksinimi Çizelge 6'dan alınan düzeltme faktörü ile çarpılmalıdır. 
Çizelge 6. Seralarda farklı 1sıtma sistemleri için düzeltme faktörleri

\begin{tabular}{|c|c|}
\hline Isıtma Sistemi & 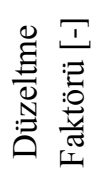 \\
\hline Yükseğe yerleştirilmiş borulu isıtma & 1,22 \\
\hline Masa altına borulu isitma sistemi & 1,10 \\
\hline Yan duvarlarda borulu isitma sistemi & 1,21 \\
\hline Isıtma boruları tabana yakın & 1,00 \\
\hline Düşük hızlı hava ısıtıcısı (1. Kademe) & 1,48 \\
\hline Orta hizlı hava 1sitıcısı $\quad$ (2. Kademe) & 1,06 \\
\hline Yüksek hızlı hava 1sıtıcısı (3. Kademe) & 1,19 \\
\hline Delikli plastik borulu hava 1sıtıcısı & 1,04 \\
\hline
\end{tabular}

\section{SONUÇ VE TARTIŞMA}

Seralarda 1S1 enerjisi gereksiniminin belirlenmesi işletme planlamasında ve yapılacak olan fizibilite hesaplamaları için gereklidir. Isı enerjisi seranın tipine, donanımına, serada arzulanan sicaklık değerlerine ve dış iklim koşullarına bağlı olarak değişmektedir. Serada 1Sı enerjisi gereksiniminin belirlenmesi genelde ortalama sicaklık değerlerinden ve isıtma zamanının kabul edilmesiyle belirlenmektedir.

Ortalama sıcaklık değerlerine göre yapılan hesaplamalarda özellikle serada sıcaklığın düşük tutulduğu koşullarda veya hava sıcaklı̆̆ının yüksek olduğu geçiş dönemlerinde elde edilen sonuçlar, gerçek değerlere göre sapmalar göstermektedir. Seralarda 1s1 enerjisinin saatlik iklim değerlerinden gidilerek belirlenmesi en sağlıklı sonuçları vermektedir. Aynı zamanda seranın termik özelliğine bağlı olarak serada ortaya çıkan sıcaklık yükselmelerinin de dikkate alınması elde edilen sonuçları daha sağlıklı kılmaktadır.

Sera kurulacak farklı yerler için saatlik iklim değerlerinin elde edilmesi ve saatlik değerlerden yararlanarak seralarda isı gereksinimi hesaplarının elle yapılması zaman alıcı ve sikıcıdır. Ayrica 1sitılmayan ve havalandırılmayan seralarda hesaplamalar için gerekli olan gerçek sıcaklık değerlerinin belirlenmesinde mantıksal ifadelerin kullanılması, hesaplamaların elle yapılmasını zorlaştırmaktadır. Belirtilen nedenle yapılan bu çalışmada seralarda 1s1 enerjisi gereksinimi ISIGER-SERA uzman sistemle saatlik iklim değerlerinden gidilerek hesaplanmıştır.

Yapılan bu çalışmada yukarıda ifade edilen dezavantajlar nedeniyle elde edilen is1 enerjisi gereksinimleri ile bölge iklimini temsil eden Isıtma-Derece-Gün değerleri arasında istatistiksel analizler yapilarak, belirlenen matematiksel ilişkiler ve grafikler yardımı ile farklı donanımlara sahip seraların 1s1 enerjisi gereksiniminin kolayca belirlenmesi mümkündür. Yapılan istatistiksel analizler sonucunda farklı donanımlara sahip seralarda ihtiyaç duyulan isı enerjisi gereksinimleri ile Isıtma-Derece-Gün (HDD) değerleri arasında yüksek güvenlikli ilişkiler elde edilmiştir.

\section{TEŞEKKÜR}

$\mathrm{Bu}$ çalıșma TÜBITTAK tarafından desteklenen 1140533 nolu proje çerçevesinde geliştirilen ISIGER-SERA uzman sistemden yararlanarak hazırlanmıştır.

\section{KAYNAKLAR}

1. De Pascale, S., Maggio, A., 2005. Sustainable Protected Cultivation at Mediterranean Climate, Perspectives and Challenges. Acta Horticulturae, 691, 29-42.

2. Campiotti, C.A., Dondi, F., 2007. ENEA Casaccia, dpt. BASE mail: campiotti@casaccia.enea.it.

3. Bot, G.P.A., 2008. Greening the Greenhouse General Consideration. Wageningen UR Greenhouse Horticulture.

4. Garcia, J.L., De la Plaza, S., Navas, L.M., Benavente, R.M., Luna, L., 1998. Evaluation of the Feasibility of Alternative Energy Sources for Greenhouse Heating J. agric. Engng Res. 69, s.107-114.

5. Baytorun, A.N., Akyüz, A., Üstün, S., 2016. Seralarda Isitma Sistemlerinin Modellemesi ve Karar Verme Aşamasında Bilimsel Verilere 
Dayalı Uzman Sistemin Geliştirilmesi. Proje No: 1140533.

6. Çanakçı, M., Emekli, Y.N., Bilgin, S., Çağlayan, N., 2013. Heating Requirement and Cost in Greenhouses: A Case Study for Mediterranean Region of Turkey. Renewable and Sustainable Energy Reviews 24, 483-490.

7. Zabeltitz, Chr. von., 2011. Integrated Greenhouse Systems for Mild Climates. Springer -Verlag Berlin Heidelberg.

8. Tantau, H.J., 1983. Heizungsanlagen im Gartenbau. Verlag Eugen Ulmer. Stuttgart.

9. Baytorun, A.N., Zaimoğlu, Z., Üstün, S., 2012. Akdeniz Bölgesi Seralarında Is1 Enerjisi Gereksiniminin ve Enerji Artırım Önlemlerinin Etkisinin Belirlenmesi. II. Ulusal Sulama ve Tarımsal Yapılar Sempozyumu. Bornova, İzmir.

10. Damrath, J., 1980. Tabellen zur Heizenergieermittlung von Gewächshäusern. Gartenbautechnische Information ITG Hannover. Heft 8 Klima Hannover.

11. Rath, T., 1992. Einsatz wissenbasierter Systeme zur Modellirung und Darstellung von Gartenbautechnischen Fachwissen am Beispiel des Hybrieden Expertensystems HORTEX. Gartenbautechnische Informationen, Heft 34, Institut für Technik im Gartenbau der Universitat Hannover.

12. Dağsöz, A.K., 1998. Sicak Sulu Kalorifer Tesisatı, Demirdöküm Teknik Yayınları No:6, İstanbul.

13. Sahal, N., 2006. Proposed Approach for Defining Climate Regions for Turkey Based on Annual Driving Rain Index and Heating Degree-Days for Building Envelope Design, Building and Environment 41,520-526.

14. Lstiburek, J.W., 2001. Hygrothermal Climate Regions, Interior Climate Classes and Durability, Proceedings of the Eighth Conference on Building Science and Technology, Toronto, Canada, pp. 319-29.

15. Bulut, H., Büyükalaca, O., Yılmaz, T., 2007. Türkiye İçin Isıtma ve Soğutma Derece-Gün Bölgeleri ULIBTK'07 16. Ulusal Isı Bilimi ve Tekniği Kongresi, 30 Mayıs-2 Haziran, Kayseri.

16. Nisen, A., Grafiadellis, M., Jiménez, R., La Malfa, G., Martinez-Garcia, P,F., Monteiro, A.,
Verlodt, H., Villele, O., Zabeltitz, C,V., Denis, J.C., Baudoin, W., \& Garnaud, J.C., 1988. Cultures Protegees en Climat Mediterranean. FAO, Rome.

17. Verlodt, H., 1990. Greenhouses in Cyprus, Protected Cultivation in the Mediterranean climate. FAO, Rome, Italy. 